\title{
A population-based study of 2347 fall-related injuries among older people in a Finnish emergency department
}

\author{
Saara K. Soukola ${ }^{1}$ Esa R. K. Jämsen ${ }^{1,2} \cdot$ Satu-Liisa K. Pauniaho $^{3}$ - Mika T. Ukkonen ${ }^{1,4}$ (D)
}

Received: 25 October 2019 / Accepted: 2 January 2020 / Published online: 13 January 2020

(c) The Author(s) 2020

\section{Key summary points}

Aim The main objective in this population-based study was to analyze the incidence of fall-related emergencydepartment visits and recurrent falls among older people in a Finnish community.

Findings Thirteen percent of all ED visits of patients aged 80 years and over are fall-related. One in four ofthose discharged home had a new fall-related injury.

Message As the risk of subsequent fall-related injuries was high during the first month after the fall, weemphasize the need to intervene with the fall risk promptly.

\begin{abstract}
Purpose Fall-related injuries are a significant cause of morbidity, mortality and functional decline among older people. The aim of this study is to analyze the incidence of fall-related emergency department (ED) visits and compare the characteristics of single and recurrent fallers in a population-based sample.

Methods Consecutive patients aged $\geq 80$ years and living in the Tampere city region who visited collaborative emergency department within a two-year study period (1 January 2015 to 31 December 2016) due to fall-related injury were included. The incidence of fall-related injuries and recurrent falls was calculated using population statistics.

Results A total of $6915 \geq 80$-year-old patients visited our ED 17,769 times during the study period. Thirteen percent of these visits ( $n=2347$, median 87 years, 80-103 years; 74\% female) were fall-related. The incidence of fall-related ED visits increased from 94/1000 person-years to 171/1000 among those aged 80-89 years and $\geq 90$ years, respectively. Twenty-four percent of patients had recurrent falls (range 2-5) during the observational period. Twenty-five percent of those discharged home had a subsequent fall-related injury within one month after the index visit. The distribution of diagnoses was similar among those with single and recurrent falls.

Conclusion Fall-related injuries are a significant health issue. Almost one in eight of all ED visits were fall-related, and 24\% of patients had recurrent fall-related injuries. The risk of subsequent injury was high during the first month after the first injury, emphasizing the need to intervene with the fall risk promptly.
\end{abstract}

Keywords Injurious falls $\cdot$ Accidental falls $\cdot$ Aged $\cdot$ Elderly $\cdot$ Emergency services

Preliminary results of this study were presented as an oral presentation in European Society for Emergency Medicine conference (EUSEM) in 2017, Athens.

Mika T. Ukkonen

mika.ukkonen@fimnet.fi

1 Faculty of Medicine and Health Technology, Tampere University, Tampere, Finland

2 Centre of Geriatrics, Tampere University Hospital, Tampere, Finland

3 Emergency Division, Tampere University Hospital, Tampere, Finland
4 Department of Gastroenterology and Alimentary Tract Surgery, Tampere University Hospital, Teiskontie 35, 33521 Tampere, Finland 


\section{Introduction}

Fall-related injuries are common among older people. It is assumed that at least one third of those aged over 65 years suffer from falls each year [1, 2]. While 30-50\% of falls result in bruises, wounds and other minor injuries, up to $10 \%$ of falls lead to major injuries, such as traumatic brain injury or hip fracture [3, 4]. Consequently, falls are a significant contributor to morbidity, mortality and functional decline; after a major injury, older patients are at a high risk of longterm care [5-8]. Therefore, falls are also associated with significant costs $[4,9]$.

Half of those with fall-related injuries have subsequent fall-related injuries $[1,10]$. Previous studies have shown an association between fall recurrences, severe injuries and mortality [11]. Prevention relies on the identification of high-risk patients. Therefore, clinical guidelines recommend that fall patients should be carefully assessed and considered for multifactorial interventions to reduce the risk of new injuries [12]. Fall-risk assessments should include elements such as evaluation of gait, balance, physical performance and visual, cognitive or neurological impairment, and multiple tools for this purpose have been developed [13].

Given the large burden of falls and the aging population, it is important to establish risk-reduction programs for those with fall-related injuries [14]. However, the effective targeting of resources for prevention requires not only knowledge of which fall-prevention methods are effective, but also knowledge related to the magnitude of the problem. Consequently, the main objective in this population-based study was to analyze the incidence of fall-related emergency department (ED) visits and recurrent falls in a Finnish community.

\section{Materials and methods}

Consecutive patients aged $\geq 80$ years from city of Tampere (population ca. 230,000 [15]), Finland, who presented to the collaborative ED in Tampere University Hospital between 1 January 2015 and 31 December 2016 due to fall-related injuries were included in this study. In the study collaborative ED, all patients visit the same ED regardless of their indication for emergency visit and all physicians have similar options available to examine patients, i.e., the same radiological services and laboratory examinations are available to all physicians and for all patients. Specialists (i.e., internists, surgeons and neurologists), residents and other acute care physicians work alongside each other. Patients were identified from an institutional database by retrieving all ED presentations associated with the International Statistical Classification of Diseases and Related
Health Problems 10th revision (ICD-10) subclasses for falls as an external cause of accidental injuries (W00-W19, "Falls").

Patient demographics and diagnoses were retrieved from hospital records. The key factor under analysis was the incidence of fall-related injuries (ICD-10). Falls were registered only during the two-year study period. Patients with one fall-related ED visit during the study period were registered as single fallers, whereas those with multiple falls were registered as recurrent fallers. In addition, specific subgroups, e.g., those with multiple falls, were identified. Population statistics were obtained from the open database of Statistics Finland (https://pxnet2.stat.fi/).

\section{Statistical analysis}

All statistical analyses were performed using SPSS Statistics version 22 for Windows (IBM Corp, Armonk, NY, USA). The age- and gender-adjusted incidence rates were expressed as the number of ED visits per 1000 person-years. A Kaplan-Meier curve is used to illustrate the time from the first fall-related visit to subsequent new injury among patients who were discharged after the first visit.

\section{Results}

During the 24-month observational period, a total of 6944 patients aged $\geq 80$ years visited our ED and made a total of 17,769 visits. Falls contributed to $13 \%(n=2347)$ of all ED visits, and $8.0 \%$ of the whole local population aged $\geq 80$ years required ED services because of falls $(17 \%$ of those aged $\geq 90$ years). Fifty-seven percent $(n=1338)$ of older patients made a single ED visit, whereas the rest had multiple fall-related ED visits (431 patients; $1009 \mathrm{ED}$ visits, range $2-5)$. Fifty-six percent of the falls $(n=1305)$ occurred at home among those living independently, $9.8 \%$ at nursing homes $(n=230), 4.2 \%$ at healthcare facilities $(n=99)$, and $30 \%$ ( $n=713)$ occurred outside the home among those living independently. Thirty-two percent of all patients $(n=747)$ were admitted to hospital and $39 \%(n=925)$ were discharged home and the remaining $29 \%(n=675)$ to other healthcare facilities. Baseline characteristics of the study population are presented in Table 1.

The incidence of fall-related ED visits (number of fallrelated ED visits/1000 person-years) increased with age and was higher among females (Figs. 1, 2). The incidence decreased after the age of 95 . The incidence was $107 / 1000$ among those aged $\geq 80$ years, and it was 90/1000 among males and 115/1000 among females. The incidence was 94/1000 among those aged 80-89 years and 171/1000 among those aged 90 years or over. There was no major 
Table 1 Baseline characteristics of the study population

\begin{tabular}{|c|c|c|c|c|c|c|}
\hline \multirow{3}{*}{$\begin{array}{l}\text { Variable } \\
\text { Gender, female, } n(\%)^{\mathrm{a}}\end{array}$} & \multirow{2}{*}{\multicolumn{2}{|c|}{$\begin{array}{l}\text { Single fallers } \\
n=1338\end{array}$}} & \multirow{2}{*}{\multicolumn{2}{|c|}{$\begin{array}{l}\text { Recurrent fallers } \\
n=431 \text { patients } \\
\text { (1009 falls) }\end{array}$}} & \multirow{2}{*}{\multicolumn{2}{|c|}{$\begin{array}{l}\text { All fall-related ED visits } \\
n=1769 \text { patients } \\
\text { (2347 falls) }\end{array}$}} \\
\hline & & & & & & \\
\hline & 979 & $(73 \%)$ & 758 & $(75 \%)$ & 1737 & $(74 \%)$ \\
\hline Age, median $(\min -\max )^{\mathrm{a}}$ & 86 years & (80-103 years) & 87 years & (80-101 years) & 87 years & (80-103 years) \\
\hline $80-89$ years, $n(\%)$ & 994 & $(74 \%)$ & 722 & $(72 \%)$ & 1716 & $(73 \%)$ \\
\hline$\geq 90$ years, $n(\%)$ & 344 & $(26 \%)$ & 287 & $(28 \%)$ & 631 & $(27 \%)$ \\
\hline \multicolumn{7}{|l|}{ Place of fall, $n(\%)^{\mathrm{b}}$} \\
\hline Home & 727 & $(54 \%)$ & 578 & $(57 \%)$ & 1305 & $(56 \%)$ \\
\hline Nursing home & 122 & $(9 \%)$ & 108 & $(11 \%)$ & 230 & $(10 \%)$ \\
\hline Hospital & 59 & $(4 \%)$ & 40 & $(4 \%)$ & 99 & $(4 \%)$ \\
\hline Other $^{\mathrm{c}}$ & 430 & $(32 \%)$ & 283 & $(28 \%)$ & 713 & $(30 \%)$ \\
\hline \multicolumn{7}{|l|}{ Result, $n(\%)^{\mathrm{b}}$} \\
\hline Discharged home & 632 & $(47 \%)$ & 293 & $(29 \%)$ & 925 & $(39 \%)$ \\
\hline Admitted to hospital & 371 & $(28 \%)$ & 376 & $(37 \%)$ & 747 & $(32 \%)$ \\
\hline Other $^{\mathrm{d}}$ & 335 & $(25 \%)$ & 340 & $(34 \%)$ & 675 & $(29 \%)$ \\
\hline
\end{tabular}

${ }^{\text {a }}$ Percentage of patients

${ }^{b}$ Percentage of falls

${ }^{c}$ Other location, i.e., outside home (those living independently)

${ }^{\mathrm{d}}$ Other location, i.e., nursing home, primary care centers

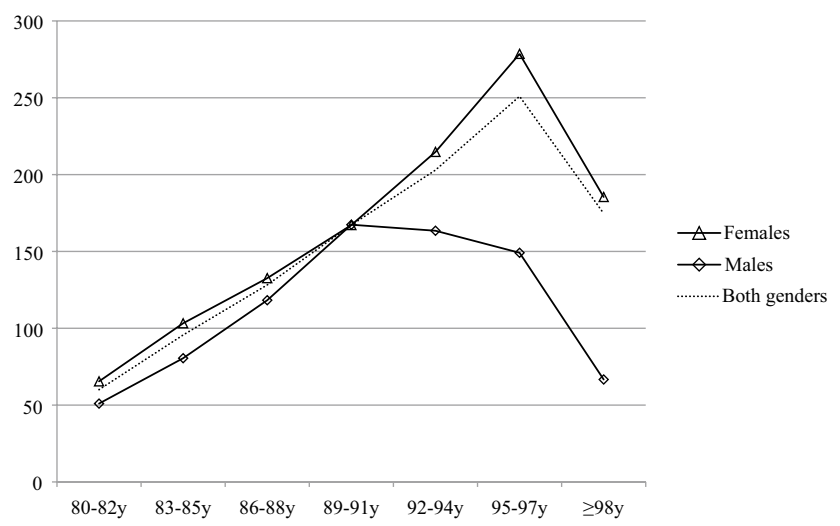

Fig. 1 Incidence of fall-related ED visits (number of ED visits/1000 person-years) monthly variation in the number of ED visits. The number of ED visits peaked at 3 p.m., and $55 \%$ of the ED visits occurred during office hours (8 a.m. to 4 p.m.), as illustrated in Fig. 3. The most common injuries caused by falls were head wounds (20/1000 person-years), intracranial injuries (19/1000) and hip fractures (16/1000). Fifty-two percent of the patients visited the ED because of one of these three injuries. The incidence of hip fractures (19/1000 vs. $11 / 1000)$, forearm fractures (10/1000 vs. 2.6/1000) and shoulder fractures (8.4/1000 vs. 2.3/1000) was higher among females than among males. The typical diagnoses in different patient populations are presented in Table 2.

Of all patients, $39 \%(n=925)$ were discharged home. Eighteen percent $(n=166)$ of those discharged home had a subsequent fall-related injury within 1 year and $21 \%$ $(n=197)$ within 2 years after the first injury. When the

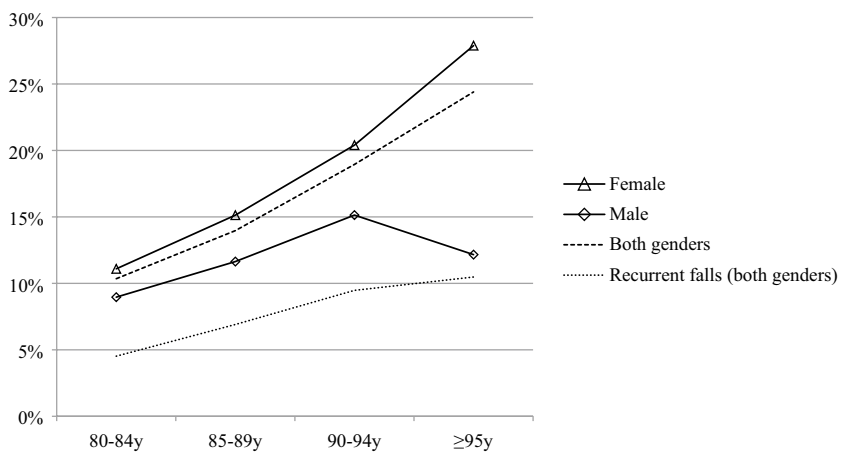

Fig. 2 Share of fall-related ED visits of all ED visits in different age groups and the share of recurrent fallers in different age groups 


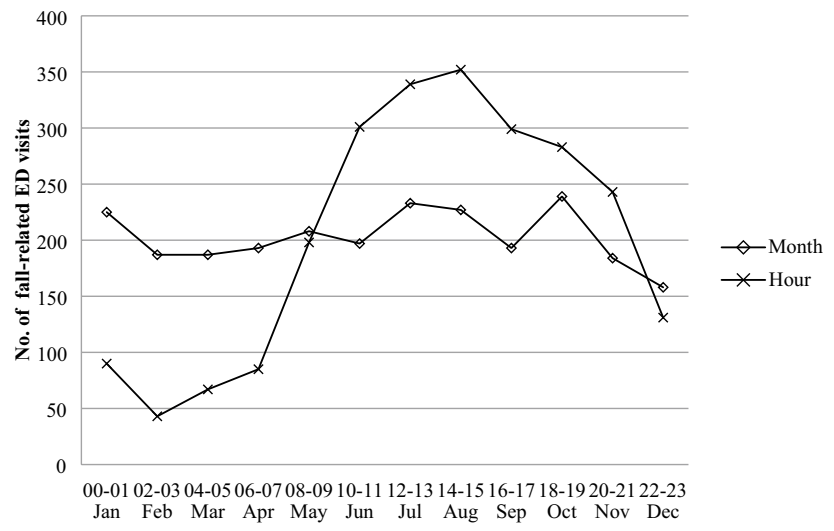

Fig. 3 Number of fall-related ED visits per month and according to the time of day

diagnostic distribution was compared between those with recurrent falls and a single fall, there was no significant difference; the same three diagnoses were the most common also among recurrent fallers. Twenty percent of recurrent fallers had a head wound $(n=199), 20 \%(n=198)$ had an intracranial injury, and $15 \%(n=152)$ had a hip fracture. Thirty-seven percent of those with recurrent falls had an injury requiring hospital admission, compared to $28 \%$ among patients with a single fall.

Among patients discharged home, the median time between the first and the subsequent fall was 123 days (0-627 days). Six percent of these patients $(n=10)$ had a subsequent injury within one week from the index ED visit and $11 \%(n=19)$ within 2 weeks, as shown in Fig. 4. The Kaplan-Meier curve, presenting time from the index ED visit to a new fall-related injury among patients discharged home after the index injury, is shown in Fig. 5.

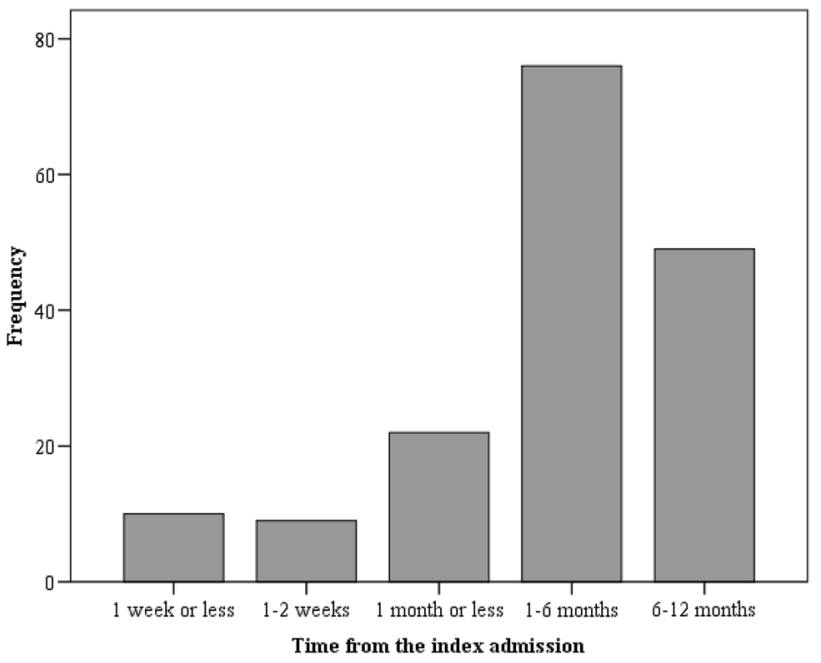

Fig. 4 The number of patients revisiting the ED at different time points after the first injurious fall

\section{Discussion}

Falls are an important public health issue and older people have a high risk of fall-related injuries. In this study, we concur with previous studies that fall-related injuries constitute a significant share of all ED visits among older people. Almost one in eight of all ED visits among patients aged $\geq 80$ years were due to injurious falls, and $24 \%$ of these patients had recurrent visits due to fall-related injuries during the 2-year study period.

The incidence of fall-related injuries observed in this study was similar to that reported in the previous literature $[16,17]$. However, including only those with an ED visit may underestimate the real incidence of injurious falls and falls in general. According to previous studies, the risk of falls is associated with older age; more than one third of
Table 2 The incidence (number of injuries/1000 person-years) of the typical fall-related injuries (according to International Statistical Classification of Diseases and Health Related Problems 10th revision, ICD-10) in the Tampere city region, Finland, 2015 and 2016

\begin{tabular}{llllll}
\hline Injury & \multicolumn{3}{l}{ Incidence } & & \multirow{2}{*}{ All } \\
\cline { 2 - 5 } & Female & Male & $80-90$ years & $\geq 90$ years & \\
\hline Head wound (S01) & 19.4 & 21.6 & 17.4 & 33.4 & 20.1 \\
Intracranial injury (S06) & 19.3 & 17.5 & 16.0 & 32.0 & 18.7 \\
Fracture of femur (S72) & 18.9 & 10.9 & 13.2 & 32.0 & 16.4 \\
Fracture of forearm (S52) & 10.3 & 2.6 & 7.2 & 10.9 & 7.9 \\
Fracture of shoulder or upper arm (S42) & 8.4 & 2.3 & 5.4 & 11.9 & 6.5 \\
Superficial injury of head (S00) & 5.8 & 2.6 & 4.2 & 7.9 & 4.8 \\
Fracture of lumbar spine or pelvis (S32) & 5.6 & 2.8 & 3.6 & 10.3 & 4.7 \\
Superficial injury of hip and thigh (S70) & 5.0 & 3.0 & 3.6 & 8.1 & 4.3 \\
Fracture of lower leg (S82) & 4.2 & 2.4 & 3.1 & 3.3 & 3.1 \\
Fracture of rib, sternum or thoracic spine (S22) & 2.7 & 2.7 & 2.3 & 4.9 & 2.8 \\
Total & 115 & 90 & 98 & 175 & 110 \\
\hline
\end{tabular}




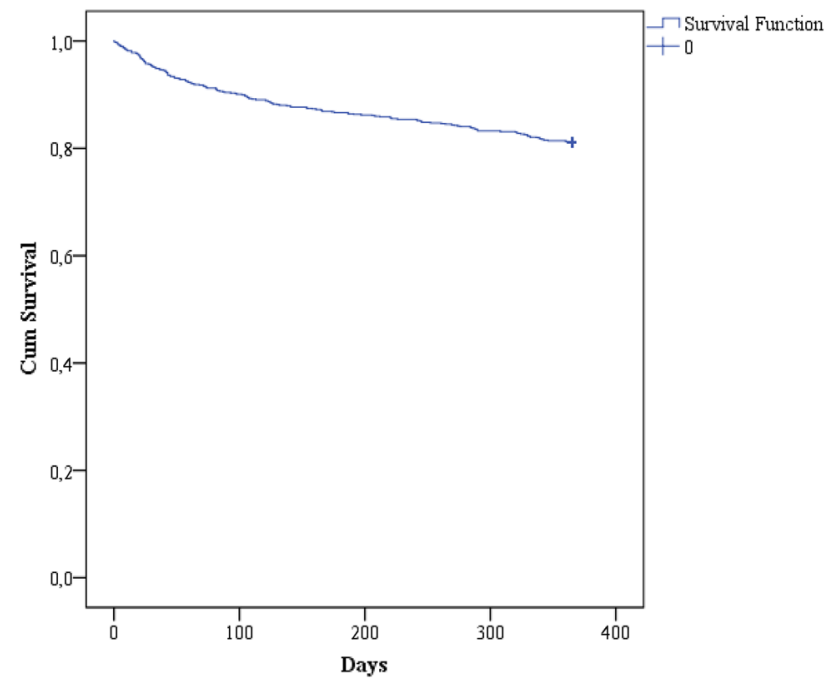

Fig. 5 Time from the first fall-related ED visit to the second ED visit, among patients who were discharged from ED after their first fall

those aged $\geq 65$ years experience falls each year, rising to over $50 \%$ by the age of 80 [4]. In this study population, nearly one quarter of the patients had had previous fallrelated injuries. Consequently, those with a high risk of fall recurrences could be a target for risk-reduction programs [18]. Previous falls have been shown to be the most important risk factor for falls among older people; thus, this finding is consistent with the existing literature. While it might not be a realistic option to educate all acute care physicians to thoroughly assess risk factors for falls, using automatic computer-assisted tools or geriatric ED nurses to perform risk assessment could be a solution [13]. In most cases, the reasons behind a fall are complex and further assessment of various risk factors is rarely possible in the ED environment. On the other hand, it is known that especially in the oldest age groups fall may be the presenting symptom of acute illness (premonitory fall), so thorough clinical assessment is warranted in addition to management of fall-related injuries.

After risk assessment, high-risk patients should be referred promptly to fall-prevention clinics or to a homebased assessment of falling risk [10]. The observation that over $10 \%$ of those with recurrent injurious falls revisited the ED within 2 weeks and 25\% within 1 month of the index ED visit underlines the need to act on fall risk without delay. During the study, over $40 \%$ of patients had multiple fall-related ED visits. As we included only those visiting ED during this 2-year period, we may have underestimated the risk of recurrent falls. In a recent study, more than half of the patients with fall-related visit had an adverse event within 6 months after the fall [19]. These events included not only recurrent falls, but other hospital admissions and deaths for example. Nevertheless, our observation may indicate that primary prevention is more crucial, since there is little time for preventive actions after the first fall [20]. In addition, it has been reported that secondary prevention of falls is inadequate [21-23].

When patients with single and recurrent falls were compared, their demographics were more alike than we had first assumed. In our study, most patients were living independently with no difference between patients with single and recurrent falls. Similarly, in a Spanish study, indoor falls with no witnesses were significantly more likely among the oldest old [24]. They also found out that non-identified causes were more common among the oldest old. In our study, the distribution of diagnoses was similar among single and recurrent fallers. However, we emphasize that the risk of major injuries (e.g., hip fracture, intracranial injuries) is not only associated with recurrent falls but also first falls. This reinforces the importance of primary prevention.

This study has some obvious limitations. First, we described ED use in a single Finnish community. However, by focusing on this specific population we were able to access accurate data on all ED visits and population statistics. Furthermore, the advantage is that our study hospital is a high-volume ED with the number of visits to physicians exceeding 90,000 per year. A second limitation, as already noted, is that some minor injuries, especially among nursing home residents, may have been treated by the staff without a need for ED services. Also, if the fall was associated with another acute condition (such as an infection or infarction), the data related to a fall might have remained unregistered. Thus, the incidence of falls is presumably higher than reported in this study. On the other hand, possible concurrent medical conditions, like acute diseases underlying the injurious fall, could not be investigated. Finally, some of the patients categorized as single fallers are possibly recurrent fallers, but their first fall may have occurred before the study period. These limitations may diminish the differences in patient demographics between recurrent fallers and single fallers.

In conclusion, fall-related ED visits are common among older Finns. Twenty-four percent of patients had subsequent injuries, and $25 \%$ of them presented to the ED within a month of the index injury. Consequently, patients admitted to EDs may benefit from systematic risk assessment and consideration of fall-prevention interventions.

Author contributions All authors (SS, EJ, SP and MU) contributed in the design of the study. SS and MU analyzed and interpreted the patient data, and all authors contributed (SS, EJ, SP and MU) in writing the manuscript. All authors read and approved the final manuscript.

Funding This study was conducted without any external funding. 


\section{Compliance with ethical standards}

Conflict of interest All the authors declare they have no conflicts of interest.

Ethics approval This study was performed according to the Helsinki Declaration and was approved by the institutional review board of Tampere University Hospital.

Informed consent As the study was retrospective and patients were not contacted, informed consent by participants was not required.

Open Access This article is licensed under a Creative Commons Attribution 4.0 International License, which permits use, sharing, adaptation, distribution and reproduction in any medium or format, as long as you give appropriate credit to the original author(s) and the source, provide a link to the Creative Commons licence, and indicate if changes were made. The images or other third party material in this article are included in the article's Creative Commons licence, unless indicated otherwise in a credit line to the material. If material is not included in the article's Creative Commons licence and your intended use is not permitted by statutory regulation or exceeds the permitted use, you will need to obtain permission directly from the copyright holder. To view a copy of this licence, visit http://creativecommons.org/licenses/by/4.0/.

\section{References}

1. Pohl P, Nordin E, Lundquist A, Bergström U, Lundin-Olsson L (2014) Community-dwelling older people with an injurious fall are likely to sustain new injurious falls within 5 years-a prospective long-term follow-up study. BMC Geriatr 14:1-7. https://doi. org/10.1186/1471-2318-14-120

2. Goodwin VA, Abdoul H, Whear R et al (2014) Multiple component interventions for preventing falls and fall-related injuries among older people: systematic review and meta-analysis. BMC Geriatr 14:8. https://doi.org/10.1186/1471-2318-14-15

3. Tinetti ME, Doucette J, Claus E, Marottoli R (1995) Risk factors for serious injury during falls by older persons in the community. J Am Geriatr Soc 43:1214-1221

4. Ambrose AF, Paul G, Hausdorff JM (2013) Risk factors for falls among older adults: a review of the literature. Maturitas 75:51-61. https://doi.org/10.1016/j.maturitas.2013.02.009

5. Chan V, Zagorski B, Parsons D, Colantonio A (2013) Older adults with acquired brain injury: outcomes after inpatient rehabilitation. Can J Aging 32:278-286

6. Eum RS, Seel RT, Goldstein R et al (2015) Predicting institutionalization after traumatic brain injury inpatient rehabilitation. $\mathrm{J}$ Neurotrauma 32:280-286. https://doi.org/10.1089/neu.2014.3351

7. Fransen M, Woodward M, Norton R, Robinson E, Butler M, John CA (2002) Excess mortality or institutionalization after hip fracture: men are at greater risk than women. J Am Geriatr Soc 50:685-690. https://doi.org/10.1046/j.1532-5415.2002.50163.x

8. Uriz-Otano F, Pla-Vidal J, Tiberio-López G, Malafarina V (2016) Factors associated to institutionalization and mortality over three years, in elderly people with a hip fracture-an observational study. Maturitas 89:9-15. https://doi.org/10.1016/j.matur itas.2016.04.005
9. Burns ER, Stevens JA, Lee R (2016) The direct costs of fatal and non-fatal falls among older adults-United States. J Saf Res 58:99-103. https://doi.org/10.1016/j.jsr.2016.05.001

10. Tinetti ME, Kumar C (2010) The patient who falls: "It's always a trade-off". JAMA 303:258-266. https://doi.org/10.1001/ jama.2009.2024

11. Sylliaas H, Idland G, Sandvik L, Forsen L, Bergland A (2009) Does mortality of the aged increase with the number of falls? Results from a nine-year follow-up study. Eur J Epidemiol 24:351-355. https://doi.org/10.1007/s10654-009-9348-5

12. NICE Clin Guidel (2013) Falls in older people : assessing risk and prevention. https://www.nice.org.uk/guidance/cg161/resources/ falls-in-older-people-assessing-risk-and-prevention-3510968672 8645. Accessed 25 Dec 2019

13. Perell KL, Nelson A, Goldmn RL, Luther SL, Prieto-Lewis N (2001) Fall risk assessment measures: an analytic review. J Gerontol Ser A Biol Sci Med Sci 56(12):M761-M766

14. Cameron I, Gillespie L, Robertson $M$ et al (2018) Interventions for preventing falls in older people in care facilities and hospitals (Review). Cochrane database Syst Rev. https://doi. org/10.1002/14651858.CD005465.pub3

15. Official Statistics of Finland: population structure [e-publication). ISSN=1797-5379. Helsinki: Statistics Finlan. https://www.stat.fi/ til/vaerak/index.html. Accessed 25 Dec 2019

16. Høidrup S, Sørensen T, Grønbaek M, Schroll M (2003) Incidence and characteristics of falls leading to hospital treatment: a oneyear population surveillance study of the Danish population aged 45 years and over. Scand J Public Health 31:24-30

17. Johansen A, Dickens J, Jones M, Richmond P, Evans R (2011) Emergency department presentation following falls: development of a routine falls surveillance system. Emerg Med J 28:25-28. https://doi.org/10.1136/emj.2009.086330

18. Burton E, Lewin G, O'Connell H, Hill K (2018) Falls prevention in community care: 10 years on. Clin Interv Aging 13:261-269. https://doi.org/10.2147/CIA.S153687

19. Sri-On J, Tirrell GP, Bean JF, Lipsitz LA, Liu SW (2017) Revisit, subsequent hospitalization, recurrent fall, and death within 6 months after a fall among elderly emergency department patients. Ann Emerg Med 70(4):516-521.e2. https://doi.org/10.1016/j. annemergmed.2017.05.023 (Epub 2017 Jul 5)

20. Siegrist M, Freiberger E, Geilhof B et al (2016) Fall prevention in a primary care setting. Dtsch Arztebl Int 113:365-372. https:// doi.org/10.3238/arztebl.2016.0365

21. Lillevang-Johannsen M, Grand J, Lembeck M et al (2017) Falls in elderly patients are not treated according to national recommendations. Dan Med J 64:1-5

22. Salonoja M, Sjösten N, Salminen M, Aarnio P, Kivelä S-L (2010) Inadequate secondary prevention of falls in the aged. Finnish Med J 65:2931-2937

23. Donaldson MG, Khan KM, Davis JC et al (2005) Emergency department fall-related presentations do not trigger fall risk assessment: a gap in care of high-risk outpatient fallers. Arch Gerontol Geriatr 41:311-317. https://doi.org/10.1016/j.archg er.2005.04.008

Publisher's Note Springer Nature remains neutral with regard to jurisdictional claims in published maps and institutional affiliations. 